(6)

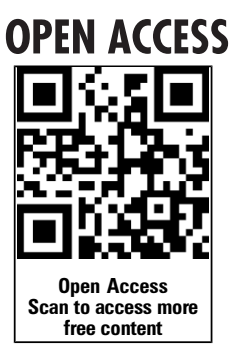

${ }^{1}$ Inserm UMR 1153 ,

Obstetrical, Perinatal and

Pediatric Epidemiology

Research Team (Epopé), Center

for Epidemiology and Statistics

Sorbonne Paris Cité, DHU Risks

in pregnancy, Paris Descartes

University, Paris, France

${ }^{2}$ Department of Public Health,

University of Copenhagen,

Copenhagen, Denmark

${ }^{3}$ Methodology and Analysis,

Statistics Denmark,

Copenhagen, Denmark

${ }^{4}$ Research Unit of Perinatal

Epidemiology, Bambino Gesu Children's Hospital, Rome, Italy

${ }^{5}$ Department of Methods and

Perinatology, BAQ, Bavarian

Institute for Quality Assurance,

Munich, Germany

${ }^{6}$ Department of Obstetrics and

Gynaecology, GROW School of Oncology and Developmental Biology, Maastricht University Medical Centre, Maastricht,

The Netherlands

${ }^{7}$ Department of Epidemiology,

Centre for Public Health,

Medical University of Vienna,

Vienna, Austria

${ }^{8}$ Department Child Health, Netherlands Organization fo Applied Scientific Research, TNO Healthy Living, Leiden, The Netherlands

\section{Correspondence to}

Dr Jennifer Zeitlin, Obstetrical, Perinatal and Paediatric Epidemiology Research Team, INSERM, Centre for

Epidemiology and Biostatistics (U1153), EPOPé, Maternité de Port Royal, 53 avenue de l'Obsenvatoire, Paris 75014, France; Jennifer.zeitlin@inserm.fr

Received 25 November 2015 Accepted 1 December 2015 Published Online First 30 December 2015

\section{CrossMark}

\section{To cite: Zeitlin J,}

Mortensen L, Cuttini M,

et al. J Epidemiol

Community Health

2016:70:609-615.

\title{
Declines in stillbirth and neonatal mortality rates in Europe between 2004 and 2010: results from the Euro-Peristat project
}

\author{
Jennifer Zeitlin, ${ }^{1}$ Laust Mortensen, ${ }^{2,3}$ Marina Cuttini, ${ }^{4}$ Nicholas Lack, ${ }_{1}^{5}$ Jan Nijhuis, ${ }^{6}$ \\ Gerald Haidinger, ${ }^{7}$ Béatrice Blondel, ${ }^{1}$ Ashna D Hindori-Mohangoo, ${ }^{8}$ and the Euro- \\ Peristat Scientific Committee
}

ABSTRACT

Background Stillbirth and neonatal mortality rates declined in Europe between 2004 and 2010. We hypothesised that declines might be greater for countries with higher mortality in 2004 and disproportionally affect very preterm infants at highest risk.

Methods Data about live births, stillbirths and neonatal deaths by gestational age (GA) were collected using a common protocol by the Euro-Peristat project in 2004 and 2010. We analysed stillbirths at $\geq 28$ weeks GA in 22 countries and live births $\geq 24$ weeks GA for neonatal mortality in 18 countries. Per cent changes over time were assessed by calculating risk ratios (RR) for stillbirth, neonatal mortality and preterm birth rates in 2010 vs 2004 . We used meta-analysis techniques to derive pooled RR using random-effects models overall, by GA subgroups and by mortality level in 2004 .

Results Between 2004 and 2010, stillbirths declined by $17 \%(95 \% \mathrm{Cl} 10 \%$ to $23 \%)$, with a range from $1 \%$ to $39 \%$ by country. Neonatal mortality declined by $29 \%$ $(95 \% \mathrm{Cl} 23 \%$ to $35 \%$ ) with a range from $9 \%$ to $67 \%$. Preterm birth rates did not change: $0 \%(95 \% \mathrm{Cl}-3 \%$ to $3 \%)$. Mortality declines were of a similar magnitude at all GA; mortality levels in 2004 were not associated with RRs.

Conclusions Stillbirths and neonatal deaths declined at all gestational ages in countries with both high and low levels of mortality in 2004. These results raise questions about how low-mortality countries achieve continued declines and highlight the importance of improving care across the GA spectrum.

\section{INTRODUCTION}

Perinatal birth outcomes have improved markedly in high-income countries over past decades: rates of neonatal mortality (deaths of live born infants in the first 28 days of life) were between 10 and $20 / 1000$ live births in the 1970s and are now under $3 / 1000$ in most countries. ${ }^{1}{ }^{2}$ Rates of stillbirth (infants born without signs of life) have also declined since the 1970s, although recent research suggests that declines have slowed or stopped in many countries. ${ }^{3}$ Despite these generally positive trends, the burden of mortality remains high, with an estimated $40000-45000$ stillbirths and neonatal deaths per year in the countries of the European Union (EU). ${ }^{13}$

There are striking inequalities in mortality between European countries. The first Euro-Peristat report documented wide variations in stillbirth and neonatal mortality rates in Europe in $2004 .{ }^{4}$ Owing to the differences in registration practices for births and deaths at very early gestations, crosscountry comparisons are often interpreted with caution or disbelief. ${ }^{5}{ }^{6}$ However, differences persist even when births most likely to be affected by registration practices are excluded. ${ }^{7}$ Further, while some of the variation was explained by higher mortality in the new member countries from the Baltic and Eastern and Central Europe, substantial differences were also observed in Western Europe.

The second Euro-Peristat report found that stillbirth and neonatal mortality rates declined between 2004 and $2010,{ }^{18}$ but the patterns of this decline and its impact on disparities between countries have not been explored. Over time, higher mortality countries may experience steeper declines in mortality, thus leading to a narrowing of the gap between countries. While audits of perinatal deaths find that between $20 \%$ and $50 \%$ of deaths are associated with suboptimal care, ${ }^{9} 10$ many fetal and neonatal deaths are not preventable-in particular, those related to lethal congenital anomalies or extremely preterm birth. Further, audits have shown that countries with lower mortality have fewer potentially preventable deaths. ${ }^{9}$ These studies raise the question of whether there is an irreducible minimum in countries with low mortality. In addition, economic development and the spread of specialised medical technology may have fuelled more rapid declines in the new member states where mortality was higher in 2004.

Declines may also be greater for higher risk preterm infants in these countries because of the specialised technology and resources needed for their care. ${ }^{11}$ More generally, changes may disproportionately affect very preterm infants who face the highest risks of mortality. Recent studies have reported mortality reductions for this population, attributed to continued medical advances and more active perinatal management. ${ }^{12}{ }^{13} \mathrm{~A}$ final question relates to how much these declines reflect changes in gestation-specific mortality or whether they could result from changes in the gestational age distribution and, in particular, reductions in the preterm birth rate.

To better understand recent trends in stillbirth and neonatal mortality in Europe, we used data from the Euro-Peristat project collected in 2004 and 2010 to investigate the changes in stillbirths and neonatal mortality by gestational age and 
across countries according to their level of mortality in 2004. We hypothesised that declines would be greater for countries with higher mortality in 2004 and disproportionally affect very preterm infants.

\section{METHODS}

\section{Data sources}

This study was embedded within the Euro-Peristat project, which developed a list of valid and reliable indicators for monitoring and evaluating perinatal health in the EU and has produced perinatal health reports on 2004 and 2010 data. ${ }^{14} 8$ Twenty-five EU member states and Norway participated in data collection in 2004 and 2010. The Euro-Peristat project collects data from routine national-level population-based sources. Data come from medical birth registers, civil registration, child health systems and routine surveys, as described previously. ${ }^{14} 714$

In this study, we used aggregate data on the numbers of live births, stillbirths and neonatal deaths by gestational age for the years 2004 and 2010. Owing to missing data on mortality by gestational age, Cyprus, Greece and Spain were excluded for all comparisons and France, Germany, Hungary, Ireland and Italy were excluded for comparisons of neonatal mortality. Slovakia was excluded because birth and death registration procedures changed substantially over the study period. Thus, 22 and 18 countries were included for the analyses of stillbirths and neonatal mortality, respectively. Data for Belgium came from the Flanders region only and for the UK, data were provided separately for England and Wales, Northern Ireland and Scotland. Data from France came from national representative surveys in 2003 and 2010. For the first period, data for England and Wales were for births in 2005, and for Italy for births in 2003.

\section{Variables and definitions}

Our principal outcomes were stillbirth and neonatal mortality rates overall and by gestational age subgroup. We also calculated preterm birth rates in order to relate changes in the gestational age distribution to those observed for mortality. Euro-Peristat requests gestational age data using the best obstetrical estimate in completed weeks (ie, 28 weeks is equal to $28^{+0}$ to $28^{+6}$ weeks).

The stillbirth rate was defined as the number of deaths before or during birth at or after 28 weeks of gestation in a given year per 1000 live and stillbirths in the same year. The threshold of $\geq 28$ weeks was used because of differences in limits for registration of stillbirths and in policies towards screening for congenital anomalies and terminations of pregnancies. ${ }^{7}$ The neonatal mortality rate was defined as the number of deaths after live birth during the neonatal period (days 0-27) at or after 24 completed weeks of gestation in a given year per 1000 live births in the same year. For the Netherlands and Slovenia, we used cohort neonatal mortality rates (deaths occurring to infants born in the year), as annual rates are not reported. Births and deaths at 22-23 weeks were excluded because recording practices vary for these very early births. The preterm birth rate was defined as the per cent of live births before 37 completed weeks of gestation. To be consistent with the indicator of neonatal mortality, we excluded births at 22 and 23 weeks.

We derived gestation-specific mortality rates for the following subgroups: 24-27 weeks (for neonatal deaths only), 28-31, 3236 and $37+$ weeks. For stillbirths, a fetus at risk approach was used overall and by gestational age (ie, the rate at 28-31 weeks was defined as the number of stillbirths from 28 to 31 weeks divided by the number of fetuses in utero at 28 weeks). ${ }^{15}$

\section{Analysis strategy}

To estimate the per cent change in mortality between the 2 years, we calculated risk ratios (RR) with 95\% CIs for each outcome in 2010 vs 2004 . We used meta-analysis techniques to derive pooled RR using random-effects models with the method of DerSimonian and Laird. Random-effects measures are interpretable as the association in an average country and relevant for inferences for the population of countries. We used Cochran's homogeneity test statistic (Q) as a measure of heterogeneity and the $\mathrm{I}^{2}$ statistic and CIs, computed using the test-based method, ${ }^{16}$ to assess the percentage of total variation between countries that is due to true heterogeneity rather than chance.

To test the hypothesis that mortality declines were greater in countries with higher mortality in 2004, pooled RR were calculated for subgroups of countries defined by their mortality in 2004. Countries with low, intermediate and high mortality in 2004 were respectively defined as a rate under the 25 th centile, between the 25 th and 75 th centiles, and above the 75 th centile. We also tested the correlation between RRs and absolute rates of mortality in 2004 using non-parametric Spearman's rank correlation tests. Spearman's rank correlation tests were also used to assess the association between changes in mortality indicators and the change in the preterm birth rate.

To further explore the impact of the change of mortality by gestational age, we estimated absolute declines in the number of deaths for each gestational age subgroup. We computed expected deaths in 2010 given the 2010 distribution of births under the assumption that gestation-specific mortality was the same as in 2004. Absolute declines were estimated as the difference between the expected and the observed number of deaths in 2010.

Analyses were performed with Stata, V.13.0 SE (Stata Corporation, College Station, Texas, USA).

\section{RESULTS}

\section{Changes in stillbirth rates}

Stillbirth rates at $\geq 28$ weeks in 2010 ranged from $<2 / 1000$ total births in Czech Republic $(1.5 \% 0)$ to over $4 / 1000$ in Latvia $(4.1 \% 0)$ and France $(4.3 \% 0)$ (table 1). In 2004, rates ranged from 2.0/1000 in Finland to almost 5/1000 in Latvia (4.9\%0) and France $(4.9 \% 0)$. Stillbirth rates declined in almost all countries and were significant in seven countries (figure 1A). The pooled RR across all countries was 0.83 (95\% CI 0.77 to 0.90 ), representing a $17 \%$ decline. The heterogeneity in RRs was highly significant and the differences between the countries, as opposed to chance, accounted for an estimated $82 \%$ of the variation in the pooled rate $\left(\mathrm{p}<0.001, \mathrm{I}^{2}=82.1 \%(95 \%\right.$ CI $63.8 \%$ to $100 \%)$ ).

\section{Changes in neonatal mortality rates}

Neonatal mortality rates at $\geq 24$ weeks ranged from $1.1 / 1000$ live births in Slovenia to 4.0/1000 in Malta in 2010 and from $<2 / 1000$ live births in the Czech Republic, Luxembourg, Norway and Sweden (1.9\%0) to 5.5/1000 in Latvia in 2004 (table 1). Neonatal mortality declined in all countries except Northern Ireland and the decline was significant in 13 of 19 countries (figure 1B). The overall pooled RR was 0.71 (95\% CI 0.65 to 0.77 ), representing a $29 \%$ decline. The test for heterogeneity was significant and between country differences accounted for an estimated $67 \%$ of the variation in the pooled RR $\left(\mathrm{p}<0.001 ; \mathrm{I}^{2}=67.4 \%\right.$ (95\% CI $43.1 \%$ to $\left.\left.91.6 \%\right)\right)$.

\section{Changes in preterm birth rates}

Preterm birth rates ranged from 5.3\% to $8.8 \%$ in 2004 and from $5.4 \%$ to $8.9 \%$ in 2010 (table 1). Changes over this period 
Table 1 Stillbirth rates, neonatal mortality rates and preterm live birth rates in 2004 and 2010 in participating countries

\begin{tabular}{|c|c|c|c|c|c|c|c|c|c|c|}
\hline \multirow[b]{3}{*}{ Country/coverage } & \multicolumn{4}{|c|}{ Stillbirth rate at $\geq 28$ weeks $G A$} & \multicolumn{4}{|c|}{ Neonatal mortality rate at $\geq 24$ weeks GA } & \multicolumn{2}{|c|}{$\begin{array}{l}\text { Preterm birth rate at } \\
\geq 24 \text { weeks GA }\end{array}$} \\
\hline & \multicolumn{2}{|l|}{2004} & \multicolumn{2}{|l|}{2010} & \multicolumn{2}{|l|}{2004} & \multicolumn{2}{|l|}{2010} & \multirow{2}{*}{$\begin{array}{l}2004 \\
\text { Percentage } \\
\text { of live births }\end{array}$} & \multirow{2}{*}{$\begin{array}{l}2010 \\
\text { Percentage } \\
\text { of live births }\end{array}$} \\
\hline & Total births & Rate/1000 & Total births & Rate/1000 & Live births & Rate/1000 & Live births & Rate/1000 & & \\
\hline Belgium: Flanders & 60679 & 2.9 & 69613 & 2.8 & 60657 & 2.2 & 69614 & 2.0 & 7.9 & 7.9 \\
\hline Czech Republic & 97480 & 2.4 & 116239 & 1.5 & 97649 & 1.9 & 116376 & 1.6 & 7.0 & 8.1 \\
\hline Denmark & 64521 & 3.7 & 63223 & 2.3 & 64448 & 3.0 & 63243 & 1.5 & 6.9 & 6.3 \\
\hline Germany & 645401 & 2.6 & 634042 & 2.3 & 646214 & - & 635097 & - & 8.8 & 8.3 \\
\hline Estonia & 13939 & 3.2 & 15790 & 2.7 & 13948 & 3.9 & 15802 & 1.3 & 5.9 & 5.6 \\
\hline Ireland & 62097 & 4.3 & 75266 & 3.7 & 62013 & - & 75635 & - & 5.5 & 5.7 \\
\hline France $^{*} \dagger$ & 14540 & 4.9 & 14753 & 4.3 & 14507 & - & 14712 & - & 6.3 & 6.5 \\
\hline Italył & 539698 & 3.7 & 539749 & 2.4 & 538881 & - & 539959 & - & 6.8 & 7.3 \\
\hline Latvia & 20382 & 4.9 & 19164 & 4.1 & 20348 & 5.5 & 19136 & 3.3 & 5.7 & 5.8 \\
\hline Lithuania & 29502 & 3.9 & 30849 & 3.4 & 29466 & 4.2 & 30815 & 2.3 & 5.3 & 5.4 \\
\hline Luxembourg§ & 5658 & 2.8 & 6517 & 2.9 & 5650 & 1.9 & 6517 & 1.2 & 7.4 & 8.1 \\
\hline Hungary & 94900 & 3.7 & 90155 & 3.4 & 95018 & - & 90259 & - & 8.6 & 8.9 \\
\hline Malta & 3894 & 3.9 & 4020 & 3.5 & 3887 & 4.4 & 4016 & 4.0 & 7.2 & 7.1 \\
\hline The Netherlands & 178710 & 4.3 & 176261 & 2.9 & 178406 & 2.8 & 176249 & 2.2 & 7.3 & 7.4 \\
\hline Austria & 78874 & 2.5 & 78539 & 2.5 & 78903 & 2.5 & 78644 & 1.7 & 8.7 & 8.4 \\
\hline Poland & 356734 & 3.8 & 413150 & 3.0 & 356499 & 4.4 & 413070 & 3.1 & 6.8 & 6.5 \\
\hline Portugal & 109136 & 2.7 & 101278 & 2.4 & 109147 & 2.3 & 101269 & 1.6 & 6.8 & 7.7 \\
\hline Slovenia & 17849 & 3.5 & 22282 & 3.3 & 17838 & 2.2 & 22278 & 1.1 & 6.9 & 7.1 \\
\hline Finland & 57407 & 2.0 & 61123 & 2.0 & 57423 & 2.0 & 61126 & 1.3 & 5.5 & 5.6 \\
\hline Sweden & 100111 & 3.2 & 114649 & 2.8 & 100053 & 1.9 & 114472 & 1.3 & 6.3 & 5.8 \\
\hline $\begin{array}{l}\text { UK: England and } \\
\text { Wales }\end{array}$ & 639966 & 4.0 & 711217 & 3.8 & 639952 & 2.5 & 710862 & 2.0 & 7.5 & 7.0 \\
\hline UK: Northern Ireland & 22355 & 3.8 & 25259 & 3.4 & 22051 & 2.4 & 25252 & 3.0 & 6.6 & 7.1 \\
\hline UK: Scotland & 52860 & 4.6 & 57133 & 3.6 & 52801 & 2.5 & 57102 & 2.1 & 7.6 & 7.0 \\
\hline Norway & 57092 & 2.9 & 62106 & 2.7 & 57093 & 1.9 & 62086 & 1.3 & 7.1 & 6.3 \\
\hline
\end{tabular}

were minimal compared with those observed for mortality (figure 1C), with a pooled RR of 1.00 (95\% CI 0.97 to 1.03). There was significant heterogeneity between countries and very little variation due to chance in the pooled RR $(\mathrm{p}<0.001$; $\mathrm{I}^{2}=96.0 \%(95 \%$ CI $84.2 \%$ to $\left.100 \%)\right)$. Changes in preterm live birth rates between 2004 and 2010, as measured by RR, were not correlated with changes in stillbirths or neonatal mortality rates $(\mathrm{r} 0.05(\mathrm{p}=0.81)$ and $0.10(\mathrm{p}=0.69)$, respectively).

\section{Declines by gestational age subgroup and level of mortality in 2004}

Stillbirth rates declined in all gestational age subgroups (table 2). Declines were lower for stillbirths at 28-31 weeks (12\%) compared with 32-36 weeks (19\%) and 37 weeks and over (18\%), but CIs overlapped. Declines also occurred across low, intermediate and high-mortality countries (14\%, 17\% and 17\%, respectively). Spearman rank correlations test relating RR to rates in 2004 were not significant $(\rho=-0.33, p=0.11)$. The general gestational age pattern was observed in all three country groups, with the exception of term stillbirths in low-mortality countries which declined by $8 \%$, but CIs overlapped substantially.

Table 3 presents these data for neonatal mortality; declines were also observed across all gestational subgroups (25\%, 26\%,
$22 \%$ and $30 \%$ from 22 to 27 weeks to term, respectively). Slightly larger declines occurred among countries with high neonatal mortality rates in $2004,35 \%$, vs $25 \%$ and $29 \%$ in low and intermediate countries. The Spearman rank correlations coefficient test for the association of mortality levels in 2004 with changes between 2004 and 2010 was not significant $(\rho=$ $-0.18, \mathrm{p}=0.47)$.

\section{Declines in the number of deaths}

Figure 2 presents the additional deaths that would have occurred in participating countries in 2010 if gestational agespecific mortality had stayed the same as in 2004. For stillbirths, these were highest at 32-36 weeks (475 stillbirths) and $37+$ weeks (426 stillbirths), accounting for $80 \%$ of the total. Decreases for neonatal mortality were highest at $37+$ weeks (513 neonatal deaths) followed by 24-27 weeks (488 neonatal deaths), accounting for $68 \%$ of the total.

\section{DISCUSSION}

Stillbirth rates at 28 weeks of gestational age and over and neonatal mortality rates at 24 weeks of gestation age and over declined between 2004 and 2010 in most European countries. Overall, neonatal deaths declined more than stillbirths, but there was significant heterogeneity across countries. In contrast to our 


\section{Other topics}

\begin{tabular}{lcc} 
A Country & RR & $(\mathbf{9 5} \% \mathrm{CL})$ \\
Czech Republic & 0.61 & $(0.50-0.74)$ \\
Denmark & 0.62 & $(0.51-0.77)$ \\
Italy & 0.63 & $(0.59-0.68)$ \\
Netherlands & 0.68 & $(0.60-0.76)$ \\
Poland & 0.79 & $(0.73-0.85)$ \\
UK: Scotland & 0.80 & $(0.66-0.96)$ \\
Latvia & 0.85 & $(0.63-1.14)$ \\
Ireland & 0.85 & $(0.72-1.01)$ \\
Lithuania & 0.86 & $(0.66-1.12)$ \\
Estonia & 0.86 & $(0.57-1.31)$ \\
Sweden & 0.87 & $(0.75-1.02)$ \\
Germany & 0.88 & $(0.82-0.95)$ \\
Portugal & 0.89 & $(0.75-1.05)$ \\
France & 0.89 & $(0.63-1.24)$ \\
Malta & 0.90 & $(0.44-1.87)$ \\
Norway & 0.91 & $(0.73-1.13)$ \\
UK: Northern Ireland & 0.92 & $(0.68-1.24)$ \\
Hungary & 0.92 & $(0.79-1.07)$ \\
Slovenia & 0.94 & $(0.67-1.32)$ \\
UK: England and Wales & 0.95 & $(0.90-1.00)$ \\
Finland & 0.96 & $(0.75-1.24)$ \\
Austria & 0.99 & $(0.82-1.21)$ \\
BE: Flanders & 1.00 & $(0.81-1.22)$ \\
Luxembourg & 1.03 & $(0.53-2.00)$ \\
Pooled RR & & \\
Pon & 0.83 & $(0.77-0.90)$ \\
\hline & &
\end{tabular}

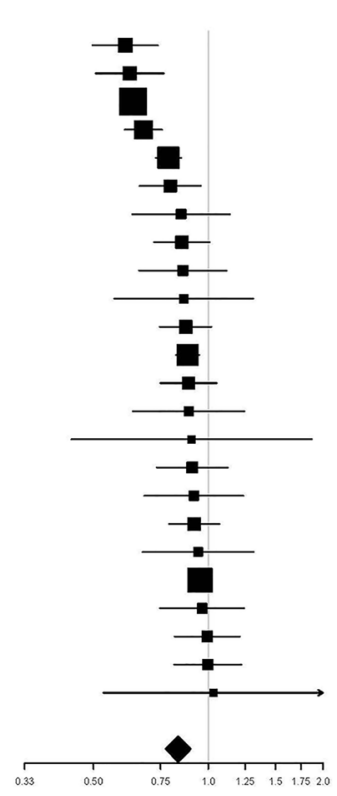

\begin{tabular}{lcc} 
B Country & RR & $(\mathbf{9 5} \% \mathrm{CL})$ \\
Estonia & 0.33 & $(0.20-0.55)$ \\
Denmark & 0.49 & $(0.39-0.63)$ \\
Slovenia & 0.50 & $(0.30-0.82)$ \\
Lithuania & 0.54 & $(0.40-0.72)$ \\
Latvia & 0.60 & $(0.44-0.81)$ \\
Luxembourg & 0.63 & $(0.25-1.57)$ \\
Finland & 0.66 & $(0.49-0.88)$ \\
Austria & 0.66 & $(0.53-0.82)$ \\
Sweden & 0.66 & $(0.53-0.82)$ \\
Norway & 0.68 & $(0.51-0.91)$ \\
Portugal & 0.69 & $(0.56-0.84)$ \\
Poland & 0.69 & $(0.65-0.75)$ \\
UK: England and Wales & 0.79 & $(0.74-0.85)$ \\
Netherlands & 0.80 & $(0.70-0.92)$ \\
UK: Scotland & 0.83 & $(0.65-1.07)$ \\
Czech Republic & 0.87 & $(0.71-1.06)$ \\
BE: Flanders & 0.90 & $(0.71-1.15)$ \\
Malta & 0.91 & $(0.46-1.80)$ \\
UK: Northern Ireland & 1.26 & $(0.88-1.79)$ \\
Pooled RR & & \\
\hline & 0.71 & $(0.65-0.77)$ \\
& &
\end{tabular}

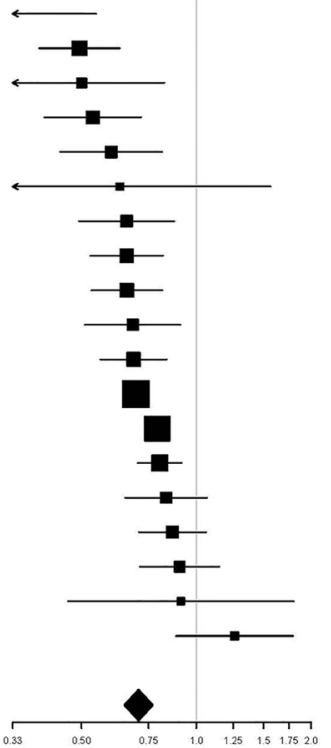

Country
Norway
UK: Scotland
Denmark
Sweden
UK: England and Wales
Germany
Estonia
Poland
Austria
Malta
BE: Flanders
Latvia
Netherlands
Finland
Lithuania
Slovenia
Ireland
Hungary
France
UK: Northern Ireland
Italy
Luxembourg
Portugal
Czech Republic
Pooled RR

$\begin{array}{ll}\text { RR } & (95 \% \mathrm{CL}) \\ 0.89 & (0.85-0.93) \\ 0.92 & (0.88-0.96) \\ 0.92 & (0.88-0.96) \\ 0.92 & (0.89-0.96) \\ 0.94 & (0.93-0.95) \\ 0.94 & (0.93-0.95) \\ 0.95 & (0.87-1.05) \\ 0.96 & (0.94-0.97) \\ 0.96 & (0.93-0.99) \\ 0.99 & (0.84-1.16) \\ 0.99 & (0.96-1.03) \\ 1.01 & (0.93-1.09) \\ 1.01 & (0.99-1.04) \\ 1.02 & (0.97-1.07) \\ 1.02 & (0.95-1.09) \\ 1.03 & (0.96-1.11) \\ 1.03 & (0.99-1.08) \\ 1.03 & (1.00-1.06) \\ 1.03 & (0.95-1.13) \\ 1.07 & (1.00-1.14) \\ 1.08 & (1.06-1.09) \\ 1.09 & (0.96-1.23) \\ 1.13 & (1.10-1.17) \\ 1.15 & (1.12-1.19) \\ & \\ 1.00 & (0.97-1.03)\end{array}$

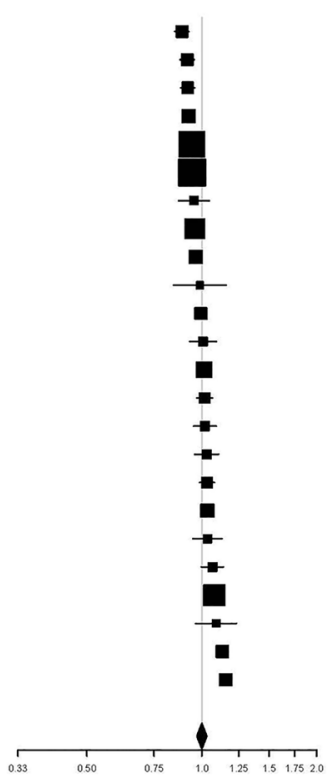

Figure 1 (A) Risk ratios (95\% Cl) of stillbirths in 2010 vs 2004 for 22 European countries. (B) Risk ratios (95\% Cl) of neonatal mortality in 2010 vs 2004 for 18 European countries. (C) Risk ratios $(95 \%$ Cl) of preterm births in 2010 vs 2004 for 22 European countries. Data from Belgium cover Flanders only and data from the UK are provided separately for England and Wales, Northern Ireland and Scotland.

Table 2 Pooled risk ratios (RRs) of stillbirths in 2010 vs 2004 overall, by mortality level in 2004 and by gestational age

\begin{tabular}{|c|c|c|c|c|}
\hline \multirow[b]{2}{*}{ All countries } & \multirow{2}{*}{$\begin{array}{l}\text { Overall } \\
\text { RR }(95 \% \mathrm{Cl}) \\
0.83(0.77 \text { to } 0.90)\end{array}$} & \multicolumn{3}{|c|}{ Gestational age subgroup } \\
\hline & & $\begin{array}{l}28-31 \text { Weeks } \\
\text { RR ( } 95 \% \mathrm{Cl}) \\
0.88(0.79 \text { to } 0.98)\end{array}$ & $\begin{array}{l}32-36 \text { Weeks } \\
\text { RR }(95 \% \mathrm{Cl}) \\
0.81(0.76 \text { to } 0.87)\end{array}$ & $\begin{array}{l}37+\text { Weeks } \\
\text { RR }(95 \% \mathrm{Cl}) \\
0.82(0.73 \text { to } 0.92)\end{array}$ \\
\hline \multicolumn{5}{|l|}{ Mortality in 2004} \\
\hline Low mortality* & $0.86(0.75$ to 0.99$)$ & 0.90 (0.70 to 1.14$)$ & 0.77 (0.65 to 0.92$)$ & 0.92 (0.75 to 1.14$)$ \\
\hline Intermediate mortality $\dagger$ & 0.83 (0.74 to 0.92 ) & 0.90 (0.76 to 1.08 ) & 0.80 (0.75 to 0.86$)$ & 0.77 (0.64 to 0.93$)$ \\
\hline High mortality $\ddagger$ & $0.83(0.71$ to 0.96$)$ & $0.86(0.68$ to 1.10$)$ & 0.80 (0.67 to 0.95$)$ & $0.82(0.69$ to 0.98$)$ \\
\hline
\end{tabular}


Table 3 Pooled risk ratios (RRs) of neonatal mortality in 2010 vs 2004 overall, by mortality level in 2004 and by gestational age

\begin{tabular}{|c|c|c|c|c|c|}
\hline \multirow[b]{2}{*}{ All countries } & \multirow{2}{*}{$\begin{array}{l}\text { Overall } \\
\text { RR }(95 \% \mathrm{Cl}) \\
0.71(0.65 \text { to } 0.77)\end{array}$} & \multicolumn{4}{|c|}{ Gestational age subgroup } \\
\hline & & $\begin{array}{l}\text { 24-27 Weeks } \\
\text { RR }(95 \% \mathrm{CI}) \\
0.75(0.66 \text { to } 0.83)\end{array}$ & $\begin{array}{l}28-31 \text { Weeks } \\
\operatorname{RR}(95 \% \mathrm{CI}) \\
0.74(0.65 \text { to } 0.83)\end{array}$ & $\begin{array}{l}32-36 \text { Weeks } \\
\text { RR }(95 \% \mathrm{CI}) \\
0.78(0.68 \text { to } 0.90)\end{array}$ & $\begin{array}{l}37+\text { Weeks } \\
\text { RR }(95 \% \mathrm{Cl}) \\
0.70(0.60 \text { to } 0.81)\end{array}$ \\
\hline \multicolumn{6}{|l|}{ Mortality in 2004} \\
\hline Low mortality* & 0.75 (0.65 to 0.88$)$ & $0.75(0.36$ to 1.15$)$ & 0.65 (0.47 to 0.92$)$ & 0.94 (0.62 to 1.44$)$ & $0.70(0.54$ to 0.90$)$ \\
\hline Intermediate mortality† & 0.71 (0.63 to 0.81$)$ & 0.74 (0.63 to 0.86$)$ & 0.79 (0.66 to 0.94$)$ & 0.77 (0.63 to 0.93$)$ & 0.71 (0.57 to 0.89 ) \\
\hline High mortality $\ddagger$ & $0.65(0.57$ to 0.75$)$ & $0.78(0.71$ to 0.86$)$ & $0.66(0.57$ to 0.77$)$ & $0.70(0.60$ to 0.82$)$ & $0.68(0.48$ to 0.96$)$ \\
\hline
\end{tabular}

initial hypotheses, these declines were not more pronounced among countries with higher mortality in 2004, indicating that continued gains occurred both in low-mortality and highmortality countries. Marked disparities remained, and in 2010, high-mortality countries still had rates double those of lower mortality countries. These declines were not driven by a change in the gestational age distribution, but by gestation-specific reductions in mortality that were not restricted to the highest risk babies but affected all gestational age subgroups. In fact, absolute declines in the number of deaths were highest for term births, followed by births between 24 and 27 weeks. For stillbirths, reductions were greatest among moderately preterm and term births. These results underscore the importance of a focus on improving outcomes across the gestational age spectrum.

This study has strengths and limitations. Euro-Peristat collects population-based data on births and deaths using a common protocol. Information is requested by week of gestation making it possible to compute gestation-specific mortality rates which are unavailable in other international databases. Owing to differences in recording practices for births and deaths in Europe, we excluded stillbirths at 22-27 weeks and neonatal deaths at

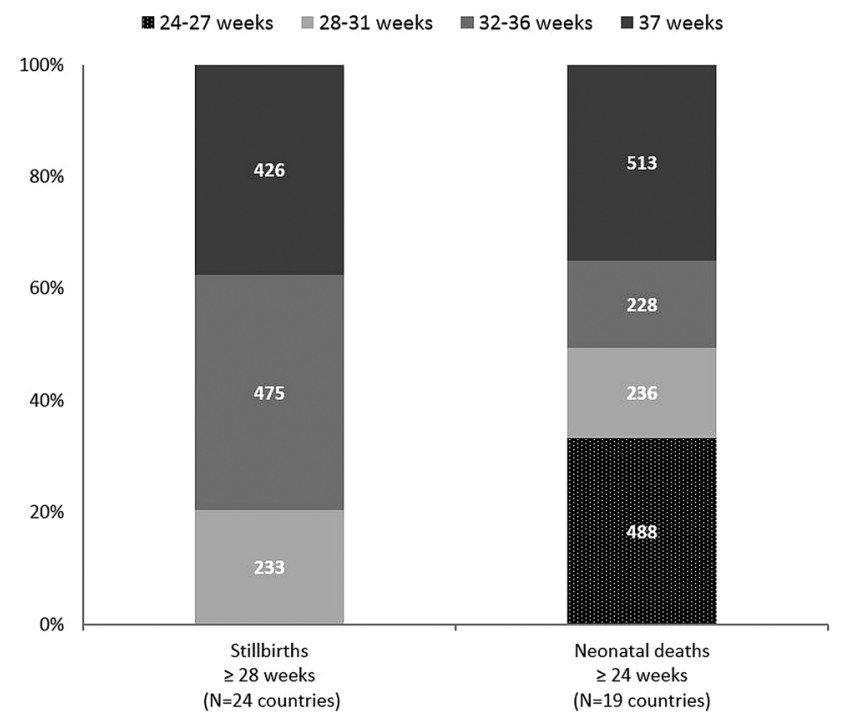

Figure 2 Estimated reduction in the number of stillbirths and neonatal deaths by gestational age subgroup in 2010 compared to 2004. Reduction computed as the difference in the number of observed and expected deaths with the number of expected deaths in 2010 calculated if gestational age-specific mortality had been the same as in 2004.
22-23 weeks, allowing like-with-like comparisons across countries and across time. ${ }^{17}$ However, owing to these exclusions, we were unable to assess changes in stillbirth before 28 weeks. Another limitation is that we had only two time points, as Euro-Peristat collects data periodically for its reports. This increases variation due to annual fluctuations, especially in small countries, and the influence of specific situations linked to the years selected for our studies. In Italy, for instance, data covering the first period were produced after institutional changes in the processing of birth certificates; weights were used to compute total numbers, a procedure that was no longer used in $2010 .^{18}$ Finally, as Euro-Peristat collects national-level aggregate data, we are limited by the lack of information on other factors to explain the observed changes in outcomes.

Our results corroborate studies showing steady declines in neonatal mortality in high-income countries, ${ }^{19}$ but contrast with some studies that have shown stagnating or increasing stillbirth rates. $^{20-22}$ Part of these differences may be related to how stillbirth rates are measured. For instance, a Canadian study found that the reported increases in stillbirth rates were due to increasing terminations of pregnancies, not spontaneous stillbirths. ${ }^{21}$ The fact that some countries count terminations of pregnancy as stillbirths, while others do not, ${ }^{14}$ is one of the justifications for Euro-Peristat 28 week inclusion threshold since terminations are rare after this gestational age in most countries. ${ }^{23}$ It is also possible that stillbirth rates have begun to decline in some countries after a period of stagnation. ${ }^{24}$

We did not find marked changes in preterm birth rates, in contrast with recent reports of declining rates from the USA, although baseline rates were higher. ${ }^{25}$ While there was substantial heterogeneity in changes in the preterm birth rate over the study period, confirming previous Euro-Peristat analyses, ${ }^{26}$ these changes were not correlated with changes in mortality. Efforts to prevent preterm births have generally been unsuccessful, 2728 although the fact that some countries have experienced declines over the past decade has spurred interest in understanding the drivers of these changes. ${ }^{29}$ Further, the relationship between higher preterm birth rates and mortality may not be straightforward as some preterm births are the result of intervention undertaken to prevent stillbirths and improve neonatal outcomes. ${ }^{30}$

Gestation-specific mortality declined at all gestational ages, suggesting that explanations are multifactorial. Several nonexclusive hypotheses can be put forth. Changes in screening policies for congenital anomalies could have lowered reported stillbirths and neonatal mortality rates if screening led to early terminations for lethal anomalies or better postnatal management of certain anomalies such as congenital heart defects. ${ }^{31}$ Studies from the Netherlands and Denmark, where declines 
were particularly steep, suggest that newly introduced screening policies may have contributed to declines. ${ }^{32} 33$ Changes may also result from other policies, including preconception counselling $^{34}$ or programmes to improve the detection of fetal growth restriction. ${ }^{24}$ The decline in the prevalence of congenital heart defects in Europe has been associated with more periconceptional use of folic acid, for instance. ${ }^{35}$ Studies also find that more very preterm infants are receiving appropriate treatments, such as antenatal steroids and surfactants. ${ }^{12}$ Finally, the increasing emphasis on quality of care in obstetrics and neonatology, through the development of clinical guidelines and audits, may have improved the outcome. ${ }^{36}$

Changes in the prevalence of risk factors in the population of childbearing women may also contribute to declines. In particular, smoking during pregnancy, considered to be the major risk factor for stillbirth, ${ }^{37}$ has decreased in many countries over this period. ${ }^{1}$ However, other risk factors for stillbirth and neonatal death—such as older maternal age and overweight-have increased and would have a negative effect on population indicators. $^{38}$

These results raise multiple questions for future research, including on the specific impact of policy initiatives as well as the relative contribution of changes in population characteristics to mortality declines. Further, we focused on stillbirth and neonatal mortality as separate indicators because of their distinct aetiological determinants in high-income countries with a high proportion of antepartum deaths and the need for different analytic approaches (fetus at risk approach for stillbirths). ${ }^{15}$ However, future studies should consider whether changes in policies related to stillbirths affect neonatal mortality and vice versa. Finally, while these results relate to countries in Europe, Euro-Peristat methodology could be applied in other countries, including middle-income and some low-income countries with population-based data of births and early prenatal care enabling accurate measurement of gestational age.

In conclusion, substantial declines in neonatal and stillbirth rates in Europe between 2004 and 2010 affected all gestational ages and were observed in high-mortality and low-mortality countries. Many low-mortality countries achieved continued decreases in rates, raising the global benchmarks for high performance for these key indicators of population health. These results also highlighted the importance of term and moderate preterm births to overall survival gains in high-mortality and low-mortality countries.

\section{What is already known on this subject}

Stillbirth and neonatal mortality rates vary greatly across the countries of Europe. Rates declined between 2004 and 2010, but whether this decline similarly affected all gestational age groups or reduced disparities between countries is not known.

\section{What this study adds}

Declines in neonatal and stillbirth rates were heterogeneous and observed both in high-mortality and low-mortality countries, resulting in continued wide disparities. Declines were not only observed among high risk very preterm births, but occurred among moderate preterm and term births.
Acknowledgements The authors would like to acknowledge the following contributors to the European Perinatal Health Report: Health and Care of Pregnant Women and Babies in Europe in 2010: Austria, Gerald Haidinger, The Medical University of Vienna, Department of Epidemiology, Centre of Public Health; Jeannette Klimont, Statistics Austria; Belgium, Sophie Alexander, Wei-Hong Zhang, Michèle Dramaix-Wilmet, Mélissa Van Humbeeck, Université Libre de Bruxelles, School of Public Health, Epidemiology, Biostatistics and Clinical Research Centre; Charlotte Leroy, Anne-Frédérique Minsart, Virginie van Leeuw, Centre d'Epidémiologie Périnatale (Cepip); Evelyne Martens, SPE (Study Center for Perinatal Epidemiology); Myriam De Spiegelaere, Brussels Health and Social Observatory, Freddy Verkruyssen, Michel Willems, FPS Economy, SMEs, Self-employed and Energy; Willem Aelvoet, The Federal Public Service (FPS) Health, Food Chain Safety and Environment; Jean Tafforeau, Francoise Renard, Denise Walckiers, Focal Point for the data collection on national health statistics for Eurostat, OECD and WHO; Deborah Cuignet, Philippe Demoulin, French Community of Belgium; Heidi Cloots, Erik Hendrickx, Anne Kongs, Flemish Agency for Care and Health; Cyprus, Pavlos Pavlou, Despina Stylianou, Theopisti Kyprianou, Ministry of Health, Health Monitoring Unit; Nicos Skordes, Pediatric Department, Makarios III Hospital; Czech Republic, Petr Velebil, Institute for the Care of Mother and Child; Denmark, Jens Langhoff Roos, Obstetrics Clinic, Rigshospitalet, Copenhagen University; Anne-Marie Nybo Anderson, Laust Hvas Mortensen, University of Copenhagen; Estonia, Luule Sakkeus, Estonian Institute for Population Studies, Tallinn University; Finland, Mika Gissler, Anna Heino, Annukka Ritvanen, THL National Institute for Health and Welfare; France, Béatrice Blondel, Marie-Hélène Bouvier Colle, Marie Delnord, Jennifer Zeitlin, National Institute of Health and Medical Research (INSERM) U1153; Anne Ego, RHEOP Register for Disabled Children and Perinatal Observatory; Grégoire Rey, National Center of Statistics for Medical Causes of Death (CépiDc), National Institute of Health and Medical Research (INSERM); Germany, Nicholas Lack, Bavarian Institute for Quality Assurance; Guenther Heller, AQUA-Institut; Anton Scharl, Department of Obstetrics and Gynaecology; Klinikum Amberg; Greece, Aris Antsaklis, Peter Drakakis, Athens University Medical School, Athens; Hungary, István Berbik, Department of Obstetrics and Gynaecology, Vaszary Kolos Teaching Hospital; Iceland, Helga Sól Ólafsdóttir, Ragnheiður I. Bjarnadottir, Hildur Harðardóttir, Brynja Ragnarsdóttir, Vigdís Stefánsdóttir Landspitali University Hospital; Sigríður Haraldsdóttir, Landlaeknis Directorate of Health; Ireland, Sheelagh Bonham, Aisling Mulligan, The Economic and Social Research Institute (ESRI), Heath Research \& Information Division; Italy, Marina Cuttini, Pediatric Hospital of Baby Jesus, Unit of Epidemiology; Cristina Tamburini, Rosaria Boldrini, General Directorate for the Health Information and Statistical System, Italian Ministry of Health; Sabrina Prati, Marzia Loghi, Cinzia Castagnaro, Stefano Marchetti, Alessandra Burgio, Central Directorate for Socio-demographic and Environmental Statistics, Italian National Institute for Statistics-ISTAT; Monica Da Frè, Epidemiology Observatory, Regional Agency for Health of Tuscany; Latvia, Janis Misins, Irisa Zile, The Centre for Disease Prevention and Control of Latvia; Lithuania, Jelena Isakova, Rita Gaidelyte, Jone Jaselione, Institute of Hygiene, Health information centre;

Luxembourg, Yolande Wagener, Guy Weber Ministry of Health, Department of Health, Division of Preventive and Social Medicine; Audrey Billy, Aline Touvrey-Lecomte, Public Health Research Center; Malta, Miriam Gatt, Department of Health Information and Research, National, Obstetric Information Systems (NOIS) Register; The Netherlands, Jan Nijhuis, Maastricht University Medical Center, Department of Obstetrics \& Gynecology, Maastricht; Karin van der Pal-de Bruin and Ashna Mohangoo, TNO Healthy Living, Department Child Health, Leiden; Peter Achterberg, National Institute for Public Health and the Environment; Chantal Hukkelhoven and Ger de Winter, The Netherlands Perinatal Registry; Anita Ravelli, Academic Medical Research Center; Greta Rijninks-van Driel, The Royal Dutch College of Midwives; Pieter Tamminga, Paediatric Association of the Netherlands; Adja Waelput, Perinatal Audit Netherlands; Patsy Elferink-Stinkens, Statistics Netherlands; Norway, Kari Klungsoyr, Medical Birth Registry of Norway, Norwegian Institute of Public Health and Department of Global Public Health and Primary Care, University of Bergen; Arild Osen, Marta Ebbing, Medical Birth Registry of Norway, The Norwegian Institute of Public Health; Poland, Katarzyna Szamotulska, National Research Institute of Mother and Child, Department of Epidemiology and Biostatistics with collaboration from The Central Statistical Office, the National Health Fund and Ministry of Health; Portugal, Henrique Barros, Sofia Correia, University of Porto Medical School, Department of Clinical Epidemiology, Predictive Medicine and Public Health; Institute of Public Health; Romania, Mihai Horga, Senior Advisor at the East European Institute for Reproductive Health, East European Institute for Reproductive Health; Alexandra Cucu, National Institute of Public Health; Slovakia, Jan Cap, National Health Information Center; Slovenia, Živa Novak-Antolič, University Medical Centre, Perinatology Unit, Ljubljana University; Ivan Verdenik, University Medical Centre, Department of Obstetrics \& Gynecology, Research Unit; Spain. Francisco Bolumar, Alcala University Medical School; Mireia Jané, Maria José Vidal, Public Health Surveillance Direction, Catalan Public Health Agency; Carmen Barona, Rosa Mas, Public Health, Generalitat Valenciana; Adela Recio Alcaide, National Institute for Statistics (INE); Sweden, Karin Gottvall, Ellen Lundqvist, The National Board of Health and Welfare, Department of Statistics, Monitoring and Evaluation, Statistics on Public Health and Social Care Unit: Switzerland, Sylvie Berrut, Swiss Federal Statistical Office, Section Health; Claudia 
König, Monika Schmid, Institut für Hebammen, ZHAW Zürcher, Hochschule für Angewandet Wissenschaften; UK, Alison Macfarlane, Nirupa Dattani, City University London; Jim Chalmers (now retired), Kirsten Monteath, Information Services Division, NHS National Services Scotland; Marie Climson, National Records of Scotland; Leslie Marr, Healthcare Improvement Scotland; Rod Gibson, Birthchoice UK; Gwyneth Thomas, Rhian Osborne, Health Statistics and Analysis Unit, Welsh Government: Russell Brown, NHS Wales Informatics Service; David Sweet, Joanne Evans, Office for National Statistics; Sinead Magill, Adele Graham, Heather Reid, Public Health Agency; Terry Falconer, Karen McConnell, Northern Ireland Maternal and Child Health, Public Health Agency (now retired); Neil McComb, Human Fertilisation and Embryology Authority.

Collaborators The Euro-Peristat Scientific Committee: Gerald Haidinger (Austria), Sophie Alexander (Belgium), Pavlos Pavlou (Cyprus), Petr Velebil (Czech Republic), Anne-Marie Nybo Andersen (Denmark), Luule Sakkeus (Estonia), Mika Gissler (Finland), Béatrice Blondel (France), Nicholas Lack (Germany), Aris Antsaklis (Greece), István Berbik (Hungary), Helga Sól Ólafsdóttir (Iceland), Sheelagh Bonham (Ireland), Marina Cuttini (Italy), Janis Misins (Latvia), Jone Jaselioniene (Lithuania), Yolande Wagener (Luxembourg), Miriam Gatt (Malta), Jan Nijhuis (the Netherlands), Karin van der Pal (Executive board member, the Netherlands), Kari Klungsoyr (Norway), Katarzyna Szamotulska (Poland), Henrique Barros (Portugal), Mihai Horga (Romania), Jan Cap (Slovakia), Natasa Tul Mandić (Slovenia), Francisco Bolúmar (Spain), Karin Gottvall (Sweden), Sylvie Berrut (Switzerland), Alison Macfarlane (UK). Project coordination: Jennifer Zeitlin, Marie Delnord, Ashna Hindori-Mohangoo.

Contributors IZ, ADHM and LM conceived of the study and developed the analysis strategy for the analysis, JZ and ADHM carried out the analyses and wrote the first draft of the paper. MC, NL, JN, GH and BB provided substantial input into the analytic strategy and revised the manuscript critically for important intellectual content. The authors, including the Euro-Peristat scientific committee members, provided substantial contributions to the acquisition and interpretation of data from their own country and approved the final version.

Funding The results from this study are based on data from the Euro-Peristat project, a European project for monitoring and evaluating perinatal outcomes on the European level. The Euro-Peristat project received funding from the European Union in the framework of the Health Programme (grant numbers 20101301 and 664691).

Competing interests None declared.

Provenance and peer review Commissioned; externally peer reviewed.

Data sharing statement Data used for this study can be requested from the Euro-Peristat project.

Open Access This is an Open Access article distributed in accordance with the Creative Commons Attribution Non Commercial (CC BY-NC 4.0) license, which permits others to distribute, remix, adapt, build upon this work non-commercially, and license their derivative works on different terms, provided the original work is properly cited and the use is non-commercial. See: http://creativecommons.org/ licenses/by-nc/4.0/

\section{REFERENCES}

1 Euro-Peristat project with SCPE and EUROCAT. European Perinatal Health Report. The Health and Care of pregnant women and babies in Europe in 2010. 2013.

2 Eurostat. Infant mortality rates [demo_minfind]. 1990-2010. http://appsso.eurostat. ec.europa.eu/nui/show.do?dataset=demo_minfind\&lang=en (accessed 7 Jan 2015).

3 Flenady V, Middleton P, Smith GC, et al. Stillbirths: the way forward in high-income countries. Lancet 2011;377:1703-17.

4 EURO-PERISTAT project in collaboration with SCPE, EUROCAT and EURONEOSTAT. Better statistics for better health for pregnant women and their babies in 2004. European Perinatal Health Report 2008. 2008. http://www.europeristat.com

5 Joseph KS, Liu S, Rouleau J, et al. Influence of definition based versus pragmatic birth registration on international comparisons of perinatal and infant mortality: population based retrospective study. BMJ 2012;344:e746.

6 Graafmans WC, Richardus JH, Macfarlane A, et al. Comparability of published perinatal mortality rates in Western Europe: the quantitative impact of differences in gestational age and birthweight criteria. BJOG 2001;108:1237-45.

7 Mohangoo AD, Buitendijk SE, Szamotulska K, et al. Gestational age patterns of fetal and neonatal mortality in Europe: results from the Euro-Peristat project. PLOS ONE 2011;6:e24727.

8 Zeitlin J, Mohangoo AD, Delnord M, et al. The second European Perinatal Health Report: documenting changes over 6 years in the health of mothers and babies in Europe. J Epidemiol Community Health 2013;67:983-5.

9 Richardus JH, Graafmans WC, Verloove-Vanhorick SP, et al. Differences in perinatal mortality and suboptimal care between 10 European regions: results of an international audit. BJOG 2003;110:97-105.

10 Evers AC, Nikkels PG, Brouwers HA, et al. Substandard care in antepartum term stillbirths: prospective cohort study. Acta Obstet Gynecol Scand 2011;90:1416-22.
11 Koupilova I, McKee M, Holcik J. Neonatal mortality in the Czech Republic during the transition. Health Policy 1998:46:43-52.

12 Patel RM, Kandefer S, Walsh MC, et al. Causes and timing of death in extremely premature infants from 2000 through 2011. N Engl J Med 2015;372:331-40.

13 Costeloe KL, Hennessy EM, Haider S, et al. Short term outcomes after extreme preterm birth in England: comparison of two birth cohorts in 1995 and 2006 (the EPICure studies). BMJ 2012;345:e7976.

14 Gissler M, Mohangoo AD, Blondel B, et al. Perinatal health monitoring in Europe: results from the EURO-PERISTAT project. Inform Health Soc Care 2010;35: 64-79.

15 Kramer MS, Liu S, Luo Z, et al. Analysis of perinatal mortality and its components: time for a change? Am J Epidemiol 2002;156:493-7.

16 Thorlund K, Imberger G, Johnston BC, et al. Evolution of heterogeneity (I2) estimates and their $95 \%$ confidence intervals in large meta-analyses. PLOS ONE 2012;7:e39471.

17 Mohangoo AD, Blondel B, Gissler M, et al. International comparisons of fetal and neonatal mortality rates in high-income countries: should exclusion thresholds be based on birth weight or gestational age? PLOS ONE 2013;8:e64869.

18 Cuttini M, Marini C, Bruzzone S, et al. Protection of health information in Italy: a step too far? Int J Epidemiol 2009;38:1739-40.

19 Wang $\mathrm{H}$, Liddell CA, Coates MM, et al. Global, regional, and national levels of neonatal, infant, and under-5 mortality during 1990-2013: a systematic analysis for the Global Burden of Disease Study 2013. Lancet 2014;384:957-79.

20 Ibiebele I, Coory M, Boyle F, et al. Stillbirth rates among indigenous and non-indigenous women in Queensland, Australia: is the gap closing? BJOG 2015;122:1476-83.

21 Joseph KS, Kinniburgh B, Hutcheon JA, et al. Determinants of increases in stillbirth rates from 2000 to 2010. CMAJ 2013;185:E345-51.

22 Glinianaia SV, Rankin J, Pearce MS, et al. Stillbirth and infant mortality in singletons by cause of death, birthweight, gestational age and birthweight-forgestation, Newcastle upon Tyne 1961-2000. Paediatr Perinat Epidemiol 2010;24: $331-42$.

23 Papiernik E, Zeitlin J, Delmas D, et al. Termination of pregnancy among very preterm births and its impact on very preterm mortality: results from ten European population-based cohorts in the MOSAIC study. BJOG 2008;115:361-8.

24 Gardosi J, Giddings S, Clifford S, et al. Association between reduced stillbirth rates in England and regional uptake of accreditation training in customised fetal growth assessment. BMJ Open 2013;3:e003942.

25 Gyamfi-Bannerman C, Ananth CV. Trends in spontaneous and indicated preterm delivery among singleton gestations in the United States, 2005-2012. Obstet Gynecol 2014;124:1069-74.

26 Zeitlin J, Szamotulska K, Drewniak N, et al. Preterm birth time trends in Europe: a study of 19 countries. BJOG 2013;120:1356-65.

27 lams JD, Romero R, Culhane JF, et al. Primary, secondary, and tertiary interventions to reduce the morbidity and mortality of preterm birth. Lancet 2008;371:164-75.

28 Behrman RE, Butler AS, eds. Preterm birth: causes, consequences, and prevention. Washington DC, 2007.

29 Delnord M, Blondel B, Zeitlin J. What contributes to disparities in the preterm birth rate in European countries? Curr Opin Obstet Gynecol 2015;27:133-42.

30 Kogan MD, Alexander GR, Kotelchuck $M$, et al. Trends in twin birth outcomes and prenatal care utilization in the United States, 1981-1997. JAMA 2000:284:335-41.

31 Dolk H, Loane M, Garne E, European Surveillance of Congenital Anomalies Working G. Congenital heart defects in Europe: prevalence and perinatal mortality, 2000 to 2005. Circulation 2011;123:841-9.

32 Garne E, Hansen AV, Birkelund AS, et al. Major congenital anomalies in a Danish region. Dan Med J 2014;61:A4825.

33 Baardman ME, du Marchie Sarvaas GJ, de Walle HE, et al. Impact of introduction of 20-week ultrasound scan on prevalence and fetal and neonatal outcomes in cases of selected severe congenital heart defects in The Netherlands. Ultrasound Obstet Gynecol 2014;44:58-63.

34 Shawe J, Delbaere I, Ekstrand M, et al. Preconception care policy, guidelines, recommendations and services across six European countries: Belgium (Flanders), Denmark, Italy, the Netherlands, Sweden and the United Kingdom. Eur I Contracept Reprod Health Care 2015;20:77-87.

35 Khoshnood B, Loane M, Garne E, et al. Recent decrease in the prevalence of congenital heart defects in Europe. J Pediatr 2013;162:108-13 e2.

36 Perinatale audit: De voortgang. 2011. http://www.rijksoverheid.nl/ documenten-en-publicaties/rapporten/2013/04/24/perinatale-audit-de-voortgang. html A terme sterfte 2011 (accessed 19 Feb 2015).

37 Flenady V, Koopmans L, Middleton P, et al. Major risk factors for stillbirth in high-income countries: a systematic review and meta-analysis. Lancet 2011;377:1331-40.

38 Johansson $\mathrm{S}$, Villamor $\mathrm{E}$, Altman $\mathrm{M}$, et al. Maternal overweight and obesity in early pregnancy and risk of infant mortality: a population based cohort study in Sweden. BMJ 2014;349:g6572. 